\title{
OTIMIZANDO O ENSINO E A CULTURA DO EMPREENDEDORISMO NA EDUCAÇÃO PROFISSIONAL: UM ESTUDO DE CASO NO IFCE-CAMPUS MARACANAÚ
}

Anderson de Castro Lima ${ }^{1}$, Sandro César Silveira Jucá2, Pedro Bruno Silva Lemos ${ }^{3}$, Solonildo Almeida da Silva ${ }^{4}$, Jonathan Felipe da Silva ${ }^{5}$

1 Doutorando em Ensino (RENOEN) pelo Instituto Federal de Educação, Ciência e Tecnologia do Ceará (IFCE), Fortaleza-CE, Brasil. (anderson@ifce.edu.br)

2 Doutor em Engenharia Elétrica pela Universidade Federal do Ceará, Fortaleza-CE, Brasil.

${ }^{3}$ Doutorando em Ensino (RENOEN) pelo Instituto Federal de Educação, Ciência e Tecnologia do Ceará (IFCE), Fortaleza-CE, Brasil.

${ }^{4}$ Doutor em Educação, Professor do Instituto Federal de Educação, Ciência e Tecnologia do Ceará (IFCE), Maracanaú-CE, Brasil. da Silva

${ }^{5}$ Doutorando em Ensino (RENOEN) pelo Instituto Federal de Educação, Ciência e Tecnologia do Ceará (IFCE), Fortaleza-CE, Brasil.

Recebido em: 15/11/2021 - Aprovado em: 15/12/2021 - Publicado em: 30/12/2021

DOI: 10.18677/EnciBio_2021D36

trabalho licenciado sob licença Creative Commons Attribution-NonCommercial-NoDerivatives 4.0 International License.

\section{RESUMO}

O processo educativo deve estimular novas habilidades capazes de oportunizar e otimizar o desenvolvimento de potenciais, independentemente da condição social e da área de aplicação. Nesse sentido, a Educação Empreendedora em paralelo com a construção de uma cultura de inovação abre um conjunto de opções, oportunidades e possibilidades de aprendizado, aos alunos e aos profissionais de todas as áreas, que vão além dos conceitos puramente científicos e tecnológicos, proporcionando a estes uma nova perspectiva pautada em experiências práticas vislumbrando o desenvolvimento contextualizado e o crescimento profissional, com intuito de provocar um estímulo à mudança de comportamento tradicional. Isto posto, este trabalho teve como objetivo apresentar uma síntese dos resultados obtidos do projeto Startup IFCE. O projeto foi implementado no IFCE Campus Maracanaú, localizado na região metropolitana de Fortaleza no Estado do Ceará. Em termos metodológicos, o presente estudo foi executado por meio de uma pesquisa bibliográfica e pelo desenvolvimento de um estudo de caso. Como resultados, observou-se que a realização do projeto contribuiu para a criação de uma cultura empreendedora dentro do campus, fomentando a criação de empresas inovadoras, conhecidas como startups, pelos alunos usando metodologias como modelagem de negócios, ideação e Scrum, gerando, como essa iniciativa, empreendimentos reais e sustentáveis.

PALAVRAS-CHAVE: Cultura, Empreendedorismo, Startups. 


\title{
OPTIMIZING ENTREPRENEURSHIP TEACHING AND CULTURE IN PROFESSIONAL EDUCATION: A CASE STUDY AT IFCE CAMPUS MARACANAÚ
}

\begin{abstract}
The educational process must encourage new skills capable of providing opportunities and optimizing the development of potential, regardless of social condition and area of application. In this sense, Entrepreneurship Education, in parallel with the construction of a culture of innovation, opens a set of options, opportunities and learning possibilities for students and professionals from all areas, which go beyond purely scientific and technological concepts, providing the these provide a new perspective based on practical experiences, envisioning contextualized development and professional growth, with the aim of stimulating a change in traditional behavior. That said, this work aimed to present a synthesis of the results obtained from the Startup IFCE project. The project was implemented at the IFCE Campus Maracanaú, located in the metropolitan region of Fortaleza in the State of Ceará. In methodological terms, the present study was carried out through a literature search and the development of a case study. As a result, it was observed that carrying out the project contributed to the creation of an entrepreneurial culture within the campus, fostering the creation of innovative companies, known as startups, by students using methodologies such as business modeling, ideation and Scrum, generating, with this initiative, real and sustainable business.
\end{abstract}

KEYWORDS: Culture, Entrepreneurship, Startups.

\section{INTRODUÇÃO}

A área de Ensino é, por definição, interdisciplinar. Dessa forma, a interdisciplinaridade tem papel estratégico no sentido de estabelecer uma ligação entre saberes, propor o encontro entre teoria e prática, entre a ciência e a tecnologia, entre a ciência e a arte, apresentando-se como um conhecimento que responde aos desafios do saber complexo (BRASIL, 2019).

Partindo dessas informações, verifica-se a necessidade de refletir sobre o papel do ensino do empreendedorismo para o desenvolvimento da sociedade. Essa reflexão é importante, pois ser empreendedor não se resume apenas a criar negócios e sim criar uma cultura que possibilita a autonomia dos empreendedores. Nesse sentido, o jovem empreendedor deve aliar o desenvolvimento individual com a aquisição de competências e habilidades necessárias para o exercício de liderança (MELLO; NUNES, 2018). Segundo o Documento da Área 46 de Ensino da CAPES, para desenvolver ações no ensino formal e não formal, os programas atuam em pesquisa, em ensino e em extensão (BRASIL, 2019). Isto posto, propostas centradas no ensino de empreendedorismo podem contribuir para a geração de empresas internas nas universidades e, consequentemente, para a entrega de benefícios à sociedade, assim como para a formação de profissionais qualificados ao mercado de trabalho (VALENTI; BUENO, 2020).

Nesse sentido, o IFCE Campus Maracanaú, lócus do presente estudo de caso, foi fundado no ano de 2007 e está localizado no município que, na sua concepção, foi destinado a receber indústrias de todas as áreas de produção, além de ser um dos mais populosos do estado do Ceará. Desde a inauguração do campus, muitos avanços tecnológicos ocorreram: a Internet se popularizou, houve 
expansão exponencial da Internet das Coisas (IoT), a inteligência artificial foi aplicada em grande escala, observou-se que a inserção de ferramentas e recursos tecnológicos ocasionou profundas alterações no processo de trabalho e possibilidades de empreendimentos em inúmeras áreas do setor produtivo.

Portanto, nesse cenário caracterizado por constantes mudanças, torna-se necessário rediscutir o papel e atuação das instituições de ensino. Como exposto anteriormente, existe uma mínima possibilidade de que um colegiado de professores possa criar um projeto de curso capaz de estar em sintonia com o mercado, uma vez que qualquer mudança curricular deve ser discutida em diferentes instâncias deliberativas e o resultado só será visto, em um intervalo médio de 4-5 anos depois, quando os alunos se formarem.

Nessa perspectiva, destaca-se que a velocidade de desenvolvimento de tecnologias e as novas demandas do setor produtivo impõem grandes desafios e dificuldades às instituições de ensino. Nesse contexto, o projeto que originou esse estudo de caso real propõe o fortalecimento da cultura empreendedora no corpo docente e discente da instituição com a criação de eventos voltados para o empreendedorismo, apoiando a geração das empresas Júnior e adequando as disciplinas de empreendedorismo com o foco nas novas formas de validação de negócios. Dessa forma, tal formação voltada para o empreendedorismo possibilita ao jovem decidir sobre a sua própria vida, permite que o estudante seja protagonista e autônomo, podendo realizar suas próprias escolhas (SULAME et al., 2021). Sendo assim, o projeto desenvolvido objetivou formar profissionais mais preparados, gerar novos negócios e assim revigorar a identidade do IFCE junto à comunidade local.

O projeto foi motivado após o acesso a uma pesquisa desenvolvida pela Endeavor (2016) em conjunto com o SEBRAE que entrevistou 2.230 alunos e 680 professores pertencentes a mais de 70 instituições de ensino superior de todas as regiões do país. Seu principal objetivo foi conscientizar as instituições de ensino superior sobre seu poder em contribuir com o desenvolvimento econômico e social do Brasil, atuando como um agente-chave do desenvolvimento e transformação do ecossistema empreendedor local (ENDEAVOR, 2016).

A pesquisa demonstrou que há uma clara discrepância entre a percepção dos alunos e professores sobre o papel das universidades na geração de novos negócios (ENDEAVOR, 2016). Por mais que cerca de $65 \%$ dos professores estejam satisfeitos com iniciativas de empreendedorismo dentro da universidade, a média entre os alunos é de apenas $36 \%$. Um dos motivos é o fato das faculdades não terem um programa que apoia toda a jornada do aluno que quer empreender, algo que vá além da motivação e dos primeiros passos (ENDEAVOR, 2016). As universidades têm em sua grade disciplinas sobre empreendedorismo, mas a maioria (54\%) visa apenas inspirar o aluno a empreender. Assuntos mais práticos como o de franquias (3\%) e gestão de pequenos negócios (7\%), acabam não recebendo a atenção que merecem pelas instituições de ensino superior (ENDEAVOR, 2016).

Outro grande desafio é a falta de conexão entre os professores e o mercado de trabalho (ENDEAVOR, 2016). Por mais que metade dos professores apoiem e/ou estejam relacionados ao movimento de educação empreendedora, $48 \%$ deles relataram nunca terem tido uma experiência empreendedora, sendo que $38 \%$ não tem vontade e/ou tempo para abrir seu próprio negócio (ENDEAVOR, 2016). Dos 
poucos que se aventuraram nesse ambiente, 54\% são donos de consultorias e apenas $10 \%$ deles afirmaram que seu negócio era inovador no cenário nacional.

Os professores também não se mantêm atualizados sobre o mercado de trabalho como seus alunos. Quase $50 \%$ dos alunos empreendedores conversam com executivos e empreendedores e acreditam que essa é uma boa tática para se conectar com o mercado e suas oportunidades, ao passo que apenas $6,3 \%$ dos professores fazem o mesmo. Esse cenário é insuficiente, uma vez que $70 \%$ dos alunos começaram a empreender nos últimos 5 anos e $48 \%$ abriram seu empreendimento durante a universidade.

A referida pesquisa não foi feita no local onde o projeto foi executado, porém ela reflete diretamente 0 dia a dia da instituição, pois, com 4 cursos superiores e 4 cursos de nível técnico, a instituição possui apenas dois professores da área de empreendedorismo. Além disso, esses dois professores ministram, em média, 20 horas/aula por semana, o que impacta na possível melhoria do conteúdo abordado nas aulas e por consequência, tornando-as desmotivantes para sete de cada dez alunos entrevistados pela equipe que desenvolveu o projeto Startup IFCE.

Com todas essas informações expostas, fica claro a necessidade de mudança nas formas como as universidades e instituições de ensino preparam os alunos para o mercado de trabalho. Uma vez que, caso não se efetue nenhuma modificação, progressivamente essas instituições poderão ficar obsoletas, por exemplo, áreas que não atendam às novas necessidades do setor produtivo podem ter uma demanda diminuída, assim como áreas estratégicas podem não ter uma formação suficiente, o que pode gerar déficit de profissionais e, consequentemente, afetar a sociedade. Como solução a essa problemática pode ser adotado o modelo de tríplice hélice com a participação do setor governamental, o setor privado e a academia.

Para a elaboração da fundamentação teórica, utilizaram-se artigos científicos fruto de diferentes fontes como: periódicos científicos, anais de congressos, teses e dissertações, entre outros. Ademais, convém mencionar que a análise bibliográfica foi pautada em obras publicadas em sua maioria nos últimos cinco anos (20162021). Por fim, destaca-se que o processo de identificação e seleção das referências foi realizado no decorrer do mês de outubro de 2021.

Em relação ao procedimento metodológico, a estratégia adotada foi o estudo de caso, que, de acordo com Yin (2015, p. 4), "[...] é usado em muitas situações, para contribuir ao nosso conhecimento dos fenômenos individuais, grupais, organizacionais, sociais, políticos e relacionados". A escolha do estudo de caso se deu em função do objetivo geral do trabalho requerer a apresentação dos resultados de um projeto executado no IFCE Campus Maracanaú. A abordagem escolhida neste trabalho foi de ordem quantitativa e qualitativa pois ao final do projeto pode-se mensurar os resultados obtidos com a aplicação do projeto, a se destacar a constituição de três empresas por alunos do IFCE campus Maracanaú (CAUCHICK , 2018).

\section{REFERENCIAL TEÓRICO}

O referencial teórico descrito neste trabalho objetiva discutir algumas definições importantes que norteiam a discussão a respeito da presente proposta voltada para ensino e a implementação de uma cultura do empreendedorismo na Educação Profissional. Desse modo, a seguir, serão abordados os seguintes 
conceitos: ensino do empreendedorismo, inovação, cultura empreendedora e a tríplice hélice.

\section{Ensino de Empreendedorismo}

De acordo com Dornelas (2008) o termo empreendedor tem registros desde o século XIII na língua francesa (entrepreneur), que significava assumir riscos começando algo novo. Nesse sentido, o mencionado termo abrangia as mais diversas atividades dentro da sociedade francesa, porém, a partir do século XVIII, passou a ser diretamente associado ao pensamento de crescimento econômico (DORNELAS, 2008).

Ainda segundo esse autor, o empreendedorismo se refere ao envolvimento de pessoas e processos, concomitantemente, a fim de ressignificarem ideias existentes e as implementarem a partir de ações inéditas (DORNELAS, 2008). O empreendedor tem como função reformular ou modificar um método ou maneira existente, podendo até criar algo novo objetivando aproveitar oportunidades com a premissa de obter lucros, assumindo os riscos envolvidos (TEIXEIRA et al., 2019). Outro termo importante nesse contexto, é o intraempreendedoríssimo que nada mais é do que o empreendedorismo que ocorre no âmbito interno das empresas, decorrente de ideias que possam gerar valor ou economia advinda de funcionários (PALHARES; CARVALHO, 2019).

Dolabela (2003) afirma que todos nascem com enorme potencial criativo. Desse modo, quando se fala no ensino do empreendedorismo, o indivíduo não está aprendendo conteúdo ou novas habilidades, pelo contrário, ele está estimulando conhecimentos intrínsecos dos seres humanos (DORNELAS, 2008). Portanto, as pessoas não se tornam empreendedores, mas deixam de sê-lo ao decorrer da vida, devido aos valores antiempreendedores na educação, nas relações sociais e a toda cultura comportamental conservadora da sociedade. Nesse sentido, é preciso distinguir a educação empreendedora voltada para crianças e para adultos: Dolabela (2003, p.16) afirma que "para os adultos é necessário libertar, enquanto para as crianças trata-se de impedir o aprisionamento".

Outro fator importante a ser considerado foi que a concepção do projeto partiu de um professor da área da computação, reforçando a constatação de Dolabela (2003), que informou que nos países da América do Norte ou Europa, quem geralmente leva o conteúdo empreendedor à sala de aula é o professor de administração. Todavia, o referido autor ressalta que, no contexto brasileiro, é possível encontrar profissionais de física, ciências sociais, arquitetura e urbanismo, ciências da computação, enfim, de todas as áreas do conhecimento oferecendo esse conteúdo aos alunos sendo considerado pelo autor uma inovação brasileira (DOLABELLA, 2003).

Filion (1997) citado por Teixeira et al., (2019) evidenciou que o espírito empreendedor pode ser desenvolvido mediante a influência que a cultura empreendedora pode exercer na formação de um perfil empreendedor. No entanto, Teixeira et al. (2019) observam que o desenvolvimento de um perfil empreendedor é condicionado pelo ambiente no qual o agente social está inserido, pois este é responsável por incitar o indivíduo a agir de forma empreendedora, vencendo os desafios encontrados e autorrealizando-se.

O aprendizado e o conhecimento do espírito intraempreendedor são considerados ferramentas indispensáveis para encarar as constantes e profundas 
mudanças tecnológicas e socioeconômicas encontradas atualmente (TEIXEIRA et al., 2019). Ao envolver o agente do empreendedorismo com o processo de inovação, o sucesso ocorre como consequência da junção destes, sendo que ambos são indispensáveis para as organizações públicas e privadas. A inovação em serviço não constitui "algo radical", mas sim um processo gradativo, um novo produto, uma diretriz ou um serviço público (TEIXEIRA et al., 2019).

\section{Inovação}

A definição do termo inovação é crítica quando se trabalha no âmbito do empreendedorismo pois muitos autores, muitos indivíduos utilizam essa denominação para qualquer coisa que indique algo novo (VALENTI; BUENO, 2020). A fim de clarificar esse significado, Valenti e Bueno (2020) observam que inovação significa transformar o conhecimento em produto, processo ou serviço que tenha relevância econômica ou social, que possa solucionar problemas sociais ou ambientais, e/ou gerar desenvolvimento econômico. Isso pode ser feito a partir da geração de novos conhecimentos, fazendo novos usos de conhecimentos preexistentes ou fazendo uma combinação de conhecimentos novos e já consolidados. Pode-se desenvolver um objeto que desempenha uma funcionalidade, mudar o modelo de utilidade ou aperfeiçoar um objeto que já exista. Esse mesmo conceito se aplica nas inovações de processos e serviços.

\section{Cultura empreendedora}

Segundo Mello e Nunes (2018) a cultura empreendedora é fundamental, pois representa a essência do empreendedorismo, e pode manifestar-se de várias formas. É o cenário para o fomento da inovação, da busca, seleção e identificação de oportunidades, do trabalho criativo e do trabalho mais integrado (MELLO; NUNES, 2018).

As instituições de ensino devem assumir o papel de promover a cultura empreendedora, para tanto, devem oferecer condições para o surgimento desse ambiente disponibilizando salas e pessoal qualificado para orientar os alunos empreendedores, contactar investidores e viabilizar parcerias para concretizar os investimentos. Portanto, pode-se considerar a disponibilização dessa estrutura como um ecossistema de startups que pode ser definido como um conjunto de fatores que promovem o espírito empreendedor, acompanham e apoiam o processo de desenvolvimento de empresas iniciantes e desempenham um papel no desenvolvimento do empreendedorismo, criando eventos e apoiando toda a parte burocrática durante o início da jornada (ESCALFONI et al., 2018). Em resumo, um ecossistema de startups deverá prover:

- Infraestrutura - Incubadora;

- Apoio burocrático - Um servidor dedicado a esse fim e com conhecimento adequado;

- Orientação - Acesso a professores e profissionais com experiência de mercado;

- Eventos - podendo ser palestras com profissionais experientes, hackathons (maratona de ideias para solucionar problemas) e Startup Weekends (também uma maratona de um final de semana para resolver problemas, mas que também pode gerar novas startups). 
Neste ponto, é importante definir dois termos muito utilizados no ecossistema descrito anteriormente que são startups e spin-offs. Segundo Valenti e Bueno (2020) Startup é uma empresa que busca a inovação no seu negócio, utiliza um modelo de negócio que gera valor, é escalável, repetível e trabalha com grandes incertezas e são mais ágeis em relação a empresas tradicionais. Já uma spin-off é algo que saiu de uma organização maior, por exemplo, de uma empresa grande ou de uma universidade (VALENTI; BUENO, 2020). Geralmente, uma spin-off surge de uma pesquisa, inovação ou tecnologia desenvolvida dentro da universidade.

A forma mais rápida e efetiva para as universidades e instituições de ensino licenciarem suas tecnologias é promovendo a criação de um ecossistema de startups (ESCALFONI et al., 2018). Para Valenti e Bueno (2020), a criação de startups ou spin-offs contribui para a desburocratização do processo de licenciamento das tecnologias desenvolvidas e da relação do setor privado com o setor público, uma vez que os próprios estudantes e docentes podem ser sócios dessas empresas.

\section{Tríplice hélice}

A discussão desse tópico se torna imprescindível para reforçar o processo de criação efetiva do ecossistema de startups, pois uma instituição de ensino sozinha não consegue gerar de forma sistemática empresas advindas de seus alunos. Para que isso possa ser um processo contínuo entre em cena a tríplice hélice definida por Etzkowitz e Zhou (2017) como sendo um modelo de parceria em que a universidade/ academia, a indústria e o governo, como esferas institucionais primárias, interagem para promover o desenvolvimento por meio da inovação e do empreendedorismo.

A tríplice hélice é um modelo universal que busca promover a inovação. É o segredo por trás do conhecido Vale do Silício. Apesar de um ecossistema de inovação que surja como resultado de uma configuração específica da tríplice hélice não possa ser duplicado em seu formato exato - como o Vale do Silício, por exemplo -, uma tríplice hélice com três protagonistas e vários atores coadjuvantes pode ser reproduzida em qualquer lugar do mundo como um modelo universal de inovação (ETZKOWITZ; ZHOU, 2017).

\section{MATERIAIS E MÉTODOS}

O projeto ao qual esse estudo de caso se baseia foi realizado entre os anos de 2016 à 2020 no IFCE Campus Maracanaú. A instituição possui 4 cursos de nível técnico sendo dois integrados com o nível médio, 4 cursos de nível superior e um de pós-graduação a nível de mestrado acadêmico.

O desafio de implantar a cultura empreendedora na instituição iniciou em 2016 tendo como primeira constatação a existência de um programa de empreendedorismo em execução com o nome de Corredores Digitais, promovido pela Secretaria de Ciências e Tecnologia do Estado do Ceará (SECITECE), que é realizado anualmente, mas que não estava tendo grande adesão por parte dos estudantes. Em paralelo a esse programa, foram planejadas e realizadas palestras com o tema empreendedorismo na Semana de Integração Científica (SIC), momento em que o campus dedica uma semana para apresentar projetos realizados por seus alunos e professores tanto para a comunidade interna como externa, mas também com pouca adesão dos alunos e professores. No ano de 2017, a adesão ao 
programa Corredores Digitais e as palestras oferecidas sobre o tema continuaram baixas, causando um certo receio na equipe gestora do projeto.

Em 2018, o projeto realizou entrevistas com 30 alunos e 20 professores concluindo que o problema estava na baixa adesão dos professores, pois $80 \%$ não tinham interesse ou não estavam dispostos a falarem sobre empreendedorismo em suas aulas e que, por consequência, não valorizavam iniciativas dessa natureza e assim, não liberavam seus alunos para participarem dos eventos e programas. Apesar desse dado influenciar fortemente o comportamento dos alunos, mais de $70 \%$ deles gostariam de se envolver em projetos de negócio, entretanto, de forma unânime, eles destacaram a falta de tempo e a falta de apoio. Com esses dados em mãos, foram desenvolvidos eventos que interessassem ao corpo docente e discente ao mesmo tempo. A partir do problema do baixo interesse dos alunos e professores, a equipe iniciou reuniões de discussão com a direção geral, direção de ensino e coordenadores dos cursos para pensar em estratégias a fim de resolver a problemática dessa pequena adesão da comunidade. Depois de algumas reuniões e análises das grades curriculares de cada curso, foram definidas as seguintes ações:

- Inserir uma disciplina com um processo de pré-incubação na grade dos cursos superiores;

- Definir uma data no calendário acadêmico para um evento voltado ao empreendedorismo e inovação;

- Apoiar os programas ofertados por parceiros como o SEBRAE e SECITECE;

- Finalizar o processo de oficialização de uma empresa júnior que já estava em fase de implantação.

Com essas opções, foi iniciado o trabalho para realização dessas iniciativas e constatou-se que, apesar de todo o apoio dado pela direção, ainda continuavam os problemas de baixa adesão, principalmente dos professores. Essas iniciativas devem sempre passar por contínuos processos de melhorias e, a fim de mitigar o problema da baixa adesão dos professores, foi criado um grupo formado por professores que exerciam influência nos demais chamados de agentes de inovação.

O primeiro ponto resolvido foi a baixa participação nos eventos e após várias discussões, chegou-se à conclusão de que o possível motivo da pouca adesão nos anos anteriores foi devido às palestras estarem dentro da Semana de Integração Científica (SIC). Esse evento tem como foco principal, apresentar o que está sendo feito dentro do IFCE para a comunidade externa, desse modo, o público que vinha assistir era de alunos de outras instituições e os alunos do campus que estavam presentes no evento não participavam das palestras de empreendedorismo, pois estavam apresentando seus trabalhos para os visitantes. Nesse contexto, definiu-se que o próximo evento seria em data diferente e que deveria ter temas que interessassem tanto aos professores como aos alunos, assim nasceu o Movimento de Empreendedorismo e Inovação Tecnológica (MOVEIT).

Como pode ser constatado no banner ilustrado na Figura 1, a grade foi pensada para alcançar tanto os professores, principalmente no primeiro dia, como os alunos no primeiro e segundo dia. Para garantir a participação de todos, foi solicitado à direção de ensino que o evento fosse incluído no calendário acadêmico 
do campus, permitindo assim que os professores pudessem registrar suas aulas com a participação no evento que ocorreu nos dias 28 e 29 de setembro de 2018.

Outra solução pensada para aumentar o engajamento da comunidade foi a viabilização de capacitações para os colaboradores na área de empreendedorismo, por ser considerado um assunto que não pode mais ser tratado apenas pelo professor da área de administração. Para conseguir atingir de forma mais efetiva os alunos, foram realizados estudos nas grades dos cursos de ensino superior do campus para verificar se possuíam alguma disciplina semelhante para que pudesse ser implantada a metodologia de pré-incubação com os alunos juntos em uma mesma turma, sendo que dos quatro cursos, apenas dois tinham uma disciplina de 80 horas chamada de Gestão de projetos.

\section{FIGURA 1: Banner MOVEIT}

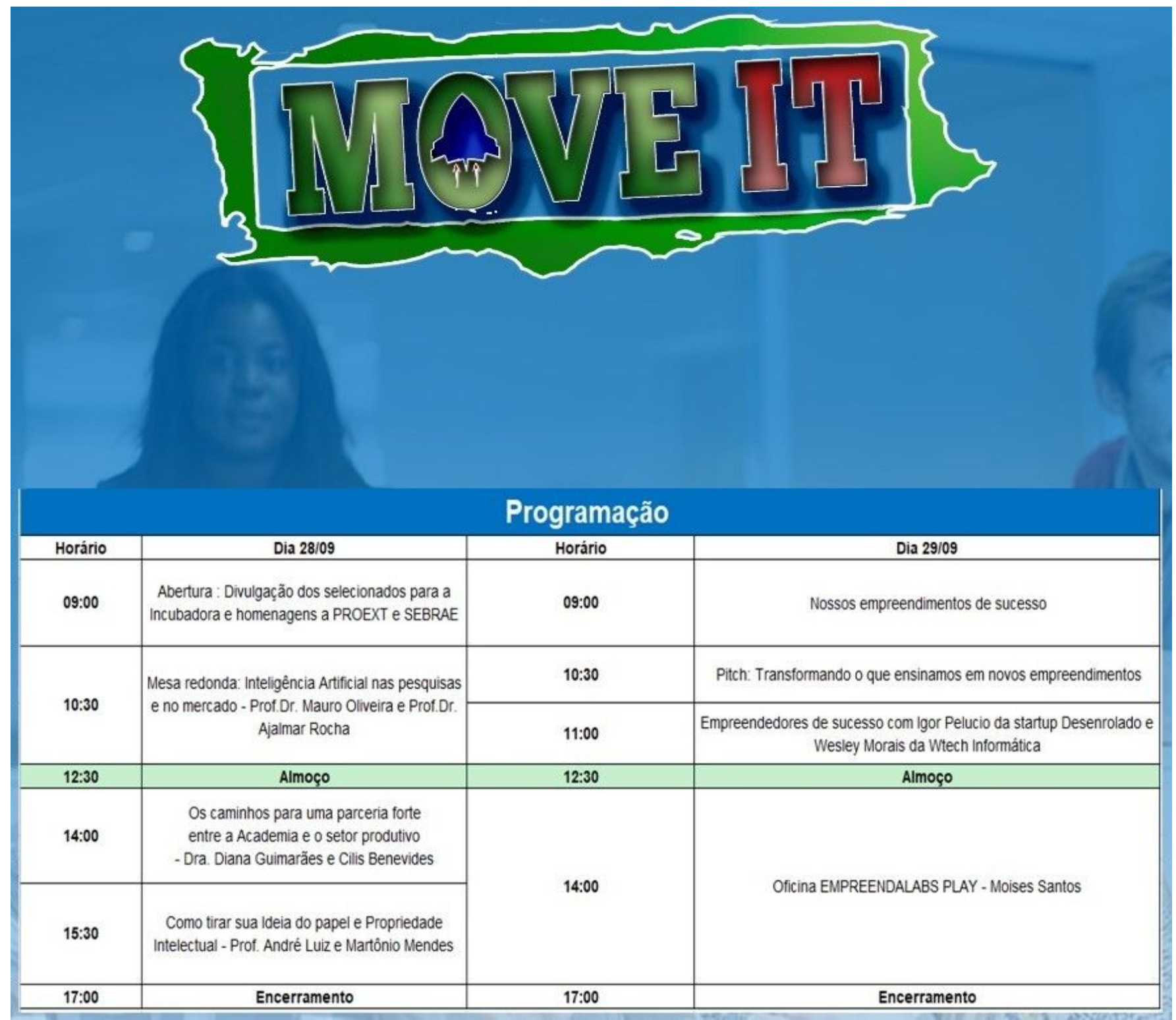

Fonte: autoria própria. 
Com essa informação, foi criado uma disciplina chamada Gestão de projetos e negócios que tinha como objetivo criar soluções para um problema real, com esse discurso a adesão dos coordenadores responsáveis pelos dois cursos que não possuíam essa disciplina foi conquistada, desse modo, ela foi inserida nas suas respectivas grades. Esse alinhamento possibilitou a integração de alunos com conhecimentos diferentes permitindo que pudessem elaborar ótimas soluções para gerar negócios e beneficiar a economia local. Os métodos da disciplina de Gestão de projetos e negócios foi baseada no quadro apresentado na Figura 2, onde os alunos iniciam sua jornada de aprendizagem seguindo a seguinte sequência:

FIGURA 2: Jornada GPN

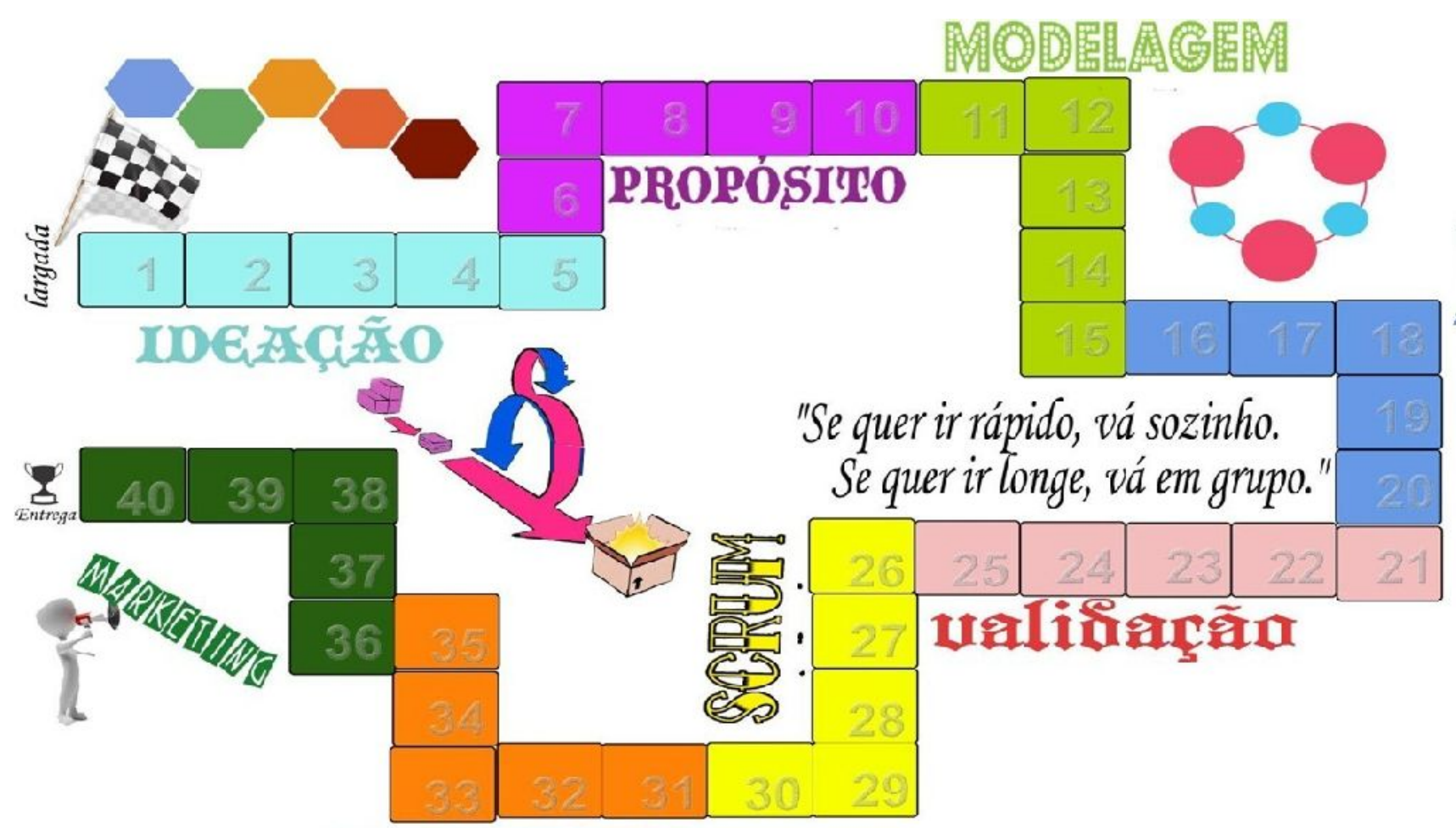

Fonte: autoria própria.

1. Ideação - Nesta fase inicial os alunos são divididos em grupos de cinco componentes. Com os grupos formados, os alunos pesam em soluções baseadas no problema central proposto na disciplina que pode ser de empresas ou órgãos públicos. A solução escolhida ainda passa por três verificações:

- Verificação se a solução é viável em termos de custo, é praticável em temos técnicos e se há equipamentos acessíveis pela equipe para desenvolver o protótipo e por último, desejável, se as pessoas beneficiadas querem a solução;

- Depois, é verificado se os conhecimentos reunidos na equipe são capazes de transformar em realidade a solução proposta dentro de um semestre; 
- Por fim, os alunos analisam o quanto de esforço eles dispenderão em relação ao impacto, ou seja, o benefício gerado pelo projeto. $\mathrm{O}$ ideal seria um esforço baixo, mas com alto impacto.

2. Propósito - Nesta fase é elaborada a proposta de valor, onde a equipe avalia se o projeto vai de encontro a uma dor real do grupo de pessoas ao qual eles escolheram como alvo para serem beneficiados;

3. Modelagem - Planejamento do funcionamento de uma empresa fictícia com foco no problema a ser resolvido proporcionando ao grupo de alunos, uma visão de como o projeto poderá ser implementado, seus custos, benefícios e como essa empresa poderá se tornar autossustentável;

4. Mapeamento - Estudo de mercado, a fim de descobrir soluções semelhantes e o que pode ser feito de diferente em relação a estas;

5. Validação - Neste ponto, é verificado a veracidade de todas as hipóteses geradas nas etapas anteriores. Dessa forma a validação do projeto proposto pode ser comprovada, ou seja, os alunos perguntam ao grupo de pessoas beneficiada com a solução se realmente todas as questões levantadas pelos alunos são verdadeiras;

6. Scrum ${ }^{1}$ - uma metodologia de gestão de projetos ágeis que não possui tradução para a língua portuguesa, que é utilizada no desenvolvimento do protótipo da solução;

7. Projeto - Planejamento do projeto a ser executado, onde é incluído a justificativa, seus riscos, quem são os apoiadores, prazos para implementação e seus custos;

8. Marketing - Esta é a etapa final da disciplina, onde os alunos aprendem sobre marketing digital e como preparar uma apresentação de negócios, que nos eventos de empreendedorismo são conhecidos como pitch.

A disciplina foi delineada com uma turma da Computação no semestre 2018.1, resultando em dois projetos, um na área de saúde e outro na área de educação. O último foi apresentado em uma batalha de pitchs, termo usado em apresentações rápidas das soluções das startups, no evento MOVEIT. Atualmente essa disciplina está em execução com a participação de acadêmicos da computação em conjunto com os alunos da engenharia mecânica e ambiental, com um resumo de seus resultados no Quadro 1.

1 O Scrum é uma metodologia que ajuda as equipes a trabalharem juntas, ele é centrado em estimular equipes a aprenderem com as experiências práticas, a se organizarem enquanto resolvem um problema e a refletirem sobre os erros e acertos para melhorias contínuas com repriorização integrada no processo. 
QUADRO 1: Resumos dos resultados da disciplina GPN

\begin{tabular}{lcc}
\hline Turma & QTD. Projetos & Solicitante \\
\hline 2018.1 & 2 & Próprios alunos \\
\hline 2018.2 & 3 & Prefeitura de Maracanaú \\
\hline 2019.1 & 4 & Empresa \\
\hline 2019.2 & 3 & Próprios alunos $^{\star}$ \\
\hline 2020.1 & 5 & Próprios alunos $^{*}$ \\
\hline 2020.2 & 4 & Próprios alunos $^{\star}$ \\
\hline 2021.1 & 5 &
\end{tabular}

Fonte: autoria própria.

* contexto da pandemia do COVID-19

RESULTADOS E DISCUSSÃO

O projeto tem uma definição clara, tem início, meio e fim, nesse estudo de caso ele apenas é chamado por esse nome devido permitir mostrar os resultados de um ciclo, porém, a cultura empreendedora deve ser sempre trabalhada e aprimorada. Nesse sentido, destacam-se que as revisões e aprimoramentos foram incorporadas conforme a realização dos ciclos que compõem o projeto. Nesta seção são apresentados os resultados dos ciclos no quadro 2:

QUADRO 2: Resumo dos resultados 2016-2020

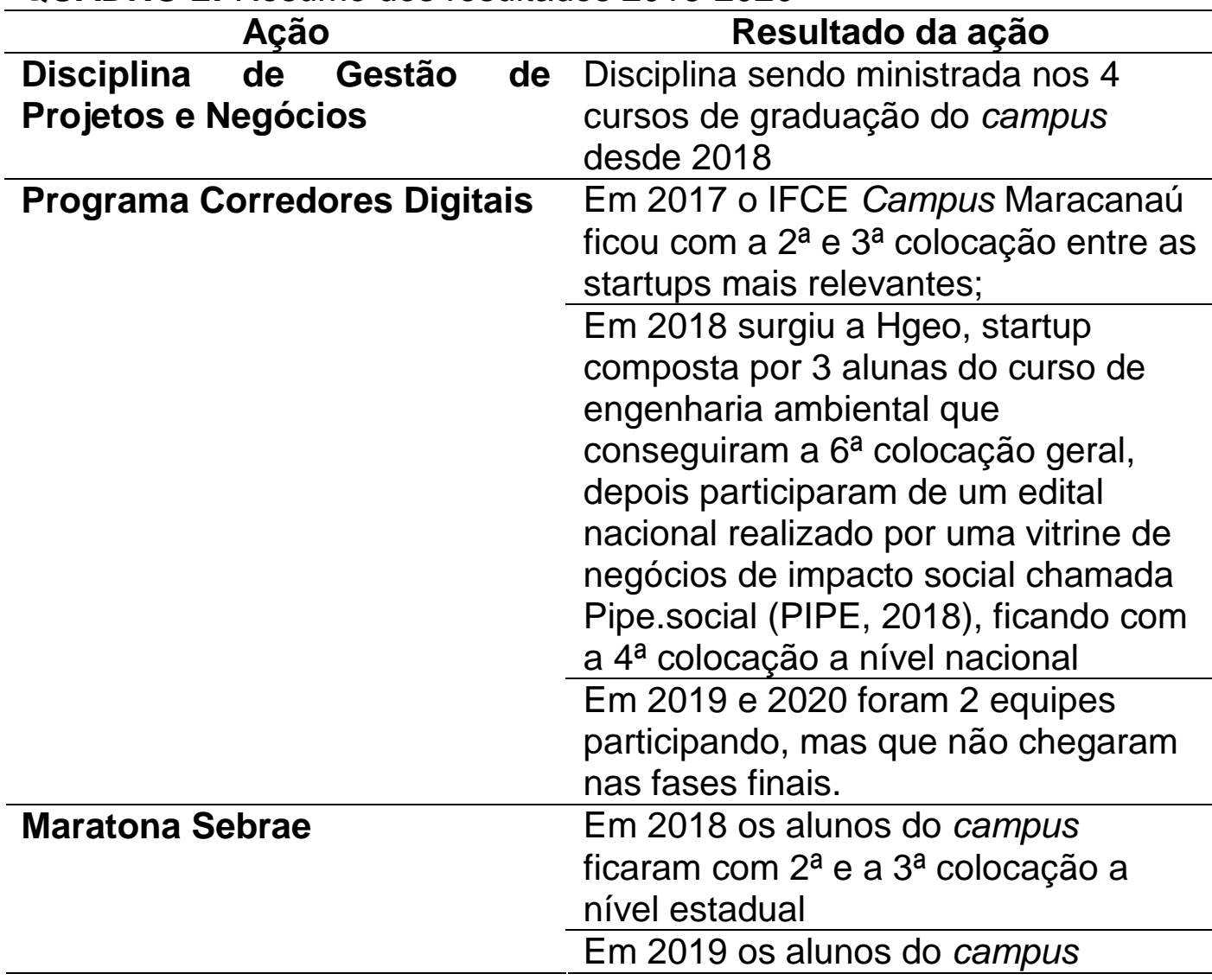




\begin{tabular}{|c|c|}
\hline & 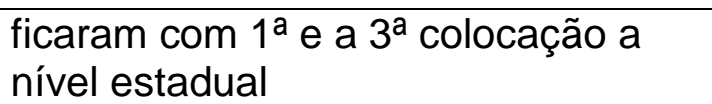 \\
\hline Empresa Júnior & $\begin{array}{l}\text { Empresa Catavento consultoria dos } \\
\text { alunos do curso de Engenharia } \\
\text { Ambiental está constituída e em } \\
\text { operação desde o início de } 2020\end{array}$ \\
\hline \multirow[t]{2}{*}{ MOVEIT } & $\begin{array}{l}\text { Em } 2018 \text { o evento ocorreu em dois } \\
\text { dias com palestras e minicursos } \\
\text { correlatos a área e atingiu mais de } \\
250 \text { pessoas entre alunos e } \\
\text { servidores }\end{array}$ \\
\hline & $\begin{array}{l}\text { Em } 2019 \text { seu formato foi aprimorado, } \\
\text { pois com o apoio de uma empresa } \\
\text { multinacional foi realizado uma } \\
\text { maratona de ideias para solucionar } \\
\text { problemas da empresa, houve a } \\
\text { participação de mais de } 60 \text { alunos só } \\
\text { na maratona e mais de } 150 \text { nas } \\
\text { palestras. }\end{array}$ \\
\hline Incubadora & $\begin{array}{l}\text { Implantada desde } 2017 \text { e em } \\
\text { funcionamento com uma empresa } \\
\text { incubada: AutoLar }\end{array}$ \\
\hline Centelha & $\begin{array}{l}\text { Em } 2020 \text { uma equipe de alunos } \\
\text { conseguiu aprovar seu projeto no } \\
\text { Programa Centelha (CENTELHA, } \\
\text { 2020) fomentado pela Fundação } \\
\text { Cearense de Apoio a Pesquisas que } \\
\text { receberam } R \$ 50 \text { mil para } \\
\text { implantação da ideia. }\end{array}$ \\
\hline Empresas constituídas & $\begin{array}{l}3 \text { empresas compostas por alunos do } \\
\text { campus foram criadas nesse ciclo: } \\
\text { - HGEO; } \\
\text { - AutoLar; } \\
\text { - Sustentap. }\end{array}$ \\
\hline
\end{tabular}

Fonte: autoria própria.

\section{CONSIDERAÇÕES FINAIS E TRABALHOS FUTUROS}

Este trabalho demonstra o resultado de um ciclo do projeto intitulado Startup IFCE, demonstra mudanças reais para o fortalecimento da cultura de empreendedorismo no IFCE Campus Maracanaú, como exposto no Quadro 2. Contudo, a consolidação de uma cultura empreendedora e, por consequência, a entrega efetiva e sistemática de frutos, ou seja, soluções que gerem inovação para o mercado são os pontos a aprimorar nesse projeto onde recomenda-se os seguintes itens de melhoria:

1. Edital de entrada para pré-incubação de fluxo contínuo;

2. Processo de pré-incubação com o uso da metodologia de gestão de projetos e negócios; 
3. Pré-incubação com conteúdo no formato de aulas online e duração de 3 meses;

4. Incubação por 3 meses em que os alunos receberão bolsas para implementar suas ideias e legalizar a startup;

5. Ao fim do ciclo de incubação, ocorrerá uma rodada com apresentações das startups para investidores anjo;

6. As startups aprovadas pelos investidores anjo passarão por mais um ciclo chamado Aceleração de mais 3 meses na instituição a fim de amadurecer o empreendimento e assim conseguir seguir com meios próprios.

A ideia proposta tenta seguir o modelo da tríplice hélice, no qual a academia entra com a infraestrutura e orientação inicial, o governo com as bolsas durante o período de incubação e o setor privado com o investimento necessário para o amadurecimento final da startup (ETZKOWITZ; ZHOU, 2017). Espera-se que seguindo essa sequência, um processo de geração de empreendimentos nascentes da instituição possa ser estabelecido, porém os resultados só poderão ser comprovados após a sua implantação que no momento da finalização deste artigo está em fase de articulação no campus que foi objeto desse estudo.

\section{REFERÊNCIAS}

BRASIL. Ministério da Educação. CAPES. Documento Orientador de APCN Área 46. Brasília. 2019. Disponível em: <https://www.gov.br/capes/pt-br/centrais-deconteudo/ensino1.pdf $>$. Acesso em: 10 nov. 2021.

CAUCHICK, M. P. A.; Metodologia de pesquisa em engenharia de produção e gestão de operações. 3a․ Ed. Rio de Janeiro: Atlas, 2018.

CENTELHA. Programa Centelha. Disponível em: <https://programacentelha.com.br/>. Acesso em: 10 nov. 2021.

DOLABELA, F. Pedagogia Empreendedora. São Paulo: Editora de Cultura, 2003.

DORNELAS, J. C. A. Empreendedorismo: Transformando Ideias em Negócios, $3^{a}$ ed. Rio de Janeiro: Elsevier, 2008.

ENDEAVOR. Empreendedorismo nas universidades: professores mais satisfeitos que alunos. Disponível em: <https://endeavor.org.br/pesquisauniversidades-empreendedorismo-2016/>. Acesso em: 10 nov. 2021.

ESCALFONI, R. E. L.; FRANÇA, T. C.; IRINEU, M. A. S.; VIVACQUA, A. S.; OLIVEIRA, J.. Um Método para Apoiar a Identificação de Interesses entre Participantes de Ecossistemas de Startups. In Proceedings of SBSI 2018 (SBSI'18). Disponível em: <https://doi.org/10.475/123_4>. doi: 10.475/123_4. Acesso em: 10 nov. 2021.

ETZKOWITZ, H.; ZHOU, C.. Hélice Tríplice: inovação e empreendedorismo universidade-indústria-governo. Estudos Avançados [online]. 2017, v. 31, n. 90, pp. 23-48. Disponível em: <https://doi.org/10.1590/s0103-40142017.3190003>. doi:0.1590/s0103-40142017.3190003. Acesso em: 10 nov. 2021. 
MELLO, M. F.; NUNES, L. D. L. S.. A importância da educação empreendedora para a cultura e formação de novos empreendedores. Saber Humano: Revista Científica da Faculdade Antonio Meneghetti, v. 8, n. 13, p. 152-173, 2018. Disponível em: <https://saberhumano.emnuvens.com.br/sh/article/view/342 >. Acesso em: 10 nov. 2021.

PALHARES, M. C.; CARVALHO, M. D. O empreendedorismo no contexto de formação do aluno graduando e pós-graduando. Revista Brasileira de Biblioteconomia e Documentação, v. 15, p. 86-112, 2019. Disponível em: <https://rbbd.febab.org.br/rbbd/article/view/1218>. Acesso em: 10 nov. 2021.

PIPE. Pipe - Negócios de Impacto. Disponível em: < https://pipe.social/>. Acesso em: 10 nov. 2021.

SALUME, P. K.; DIAS, G. F.; JUNQUEIRA, L. R.; GUIMARÃES, Liliane de Oliveira. Estimulo ao empreenderismo no ensino superior sob a perspectiva dos discentes. Revista de Administração FACES Journal, 2021. Disponível em: $<$ http://revista.fumec.br/index.php/facesp/article/view/8403>. Acesso em: 10 nov. 2021.

TEIXEIRA, T. S.; ANDRADE, Daniela Meirelles; ALCÂNTARA, V. de C.; OLIVEIRA, N. K. de. Inovação e empreendedorismo: Um caso no setor público. Revista Pretexto, p. 57-71, 2019. Disponível em: <https://doi.org/10.21714/pretexto.v20i1.5609>. doi: 10.21714/pretexto.v20i1.5609. Acesso em: 10 nov. 2021.

VALENTI, W. C.; BUENO, G. W. Inovação e empreendedorismo nas universidades do século XXI. In: VALENTINI, S.R. \& NOBRE, S.R. Universidade em Transformação. São Paulo, Editora UNESP. p. 283-304. ISBN: 978-65-5711-006-5, $2020 . \quad$ Disponível em: $<$ https://www.researchgate.net/publication/349870281_INOVACAO_E_EMPREEND EDORISMO_NAS_UNIVERSIDADES_DO_SECULO_XXI>. Acesso em: 10 nov. 2021.

YIN, R. Estudo de Caso - Planejamento e Métodos. 5a ed. Porto Alegre: Bookman, 2015. 